\title{
Computação desplugada alinhada aos descritores de Matemática do SAEB: Um relato de experiência
}

\author{
Jeanne da Silva Barbosa Bulcão', Crisiany Alves, Carlos José Nascimento', \\ Charles A. Galvão Madeira', André M. C. Campos ${ }^{1}$ \\ ${ }^{1}$ Instituto Metrópole Digital - Universidade Federal do Rio Grande do Norte(UFRN) \\ Natal - RN - Brazil \\ \{jeannebulcao1, crisianyalves@, charllos\}@gmail.com, charles@imd.ufrn.br, \\ andre@dimap.ufrn.br
}

\begin{abstract}
The search for innovation, creativity and motivation in the pedagogical practices, the unplugged games, can be a technological resource of education support, once in a playful way and through a game the possibilities of interests and absorption of educational contents are expanded. This paper presents a sequence of programming and pattern recognition activities and a game played in order to provide students with knowledge and materialize content related to 5 Prova SAEB (Prova Brasil) descriptors of Mathematics proficiency for 5th grade classes Fundamental early years.

Resumo. A busca pela inovação, criatividade e motivação nas práticas pedagógicas, os jogos desplugado, podem ser um recurso tecnológico de apoio educação, uma vez que de maneira lúdica e através de um jogo se amplia as possibilidades de interesses e internalização de conteúdos educacionais. $O$ presente artigo traz uma sequência de atividades de programação e reconhecimento de padrões e um jogo desplugado de modo a favorecer aos alunos conhecimentos e concretizar conteúdos relacionados a 5 descritores da Prova SAEB (Prova Brasil) de proficiência em Matemática para turmas do $5^{\circ}$ ano do Ensino Fundamental anos iniciais.
\end{abstract}

\section{Introdução}

O pensamento computacional tem sido estimulado desde 1960, anos depois da população dos primeiros computadores nas universidades americanas. O professor Seymour Papert, do Instituto de Tecnologia de Massachusetts, foi um dos pioneiros a incentivar o uso computador e o ensino da lógica computacional para crianças [Papert 1994].

Nas últimas décadas, pesquisadores e professores têm validado as ideias de Papert com a criação de iniciativas que visam estimular e disseminar o ensino de programação em escolas privadas e públicas em diversos países. Wing [2006] formaliza o termo pensamento computacional e indica que esse conhecimento é importante para todas as profissões, não apenas para os cientistas da computação. Portanto, deve ser ensinado em todos os níveis de ensino. Blikstein [2008] acrescenta que o desenvolvimento do pensamento computacional é necessário para que as crianças e jovens possam, no futuro, exercer sua cidadania em plenitude. O Fórum Econômico 
Mundial junta-se à discussão apontando em seu último relatório, sobre o futuro dos empregos, que a capacidade de solucionar problemas complexos é vista como uma das habilidades mais importantes e necessárias aos futuros profissionais, independente de sua área de formação [WEF 2018].

Alinhando com as tendências mundiais, o Brasil recentemente aprovou a Base Nacional Comum Curricular (BNCC) [BNCC 2018] e incluiu 10 competências que os estudantes devem alcançar até a última etapa da educação básica. Essas competências, chamadas de gerais, estão relacionadas àquelas identificadas no cenário internacional como necessárias a formação dos cidadãos e profissionais do século XXI. Dentre as competências, destacam-se aquelas que estão intrinsecamente interligadas ao pensamento computacional, quais sejam o pensamento científico, crítico, criativo; a comunicação; a cultura digital; a argumentação e a empatia e cooperação.

Para contribuir com a implementação da competência relacionada a cultura digital e o ensino do pensamento computacional, o Centro de Inovação para Educação Brasileira (CIEB) criou um currículo de referência em tecnologia e computação que pode auxiliar os professores, coordenadores e gestores das escolas públicas e privadas na efetivação da base [CIEB 2018].

Inspirado no CIEB e em outras propostas para integração do pensamento computacional nas práticas educativas, este artigo visa descrever a aplicação e as contribuições de uma proposta pedagógica para estimular o pensamento computacional alinhado aos descritores do Sistema de Avaliação da Educação Básica (SAEB) [INEP 2019]. A proposta pedagógica foi estruturada para atender a necessidade da escola em melhorar o desempenho dos estudantes em relação às habilidades avaliadas pelo SAEB.

A investigação que levou à criação da proposta pedagógica, objeto de relato deste artigo, partiu da seguinte questão: Como estimular o pensamento computacional nos estudantes do $5^{\circ}$ ano alinhado aos descritores de matemática da avaliação do SAEB? O objetivo da pesquisa era demonstrar como o pensamento computacional pode ser estimulado de forma interdisciplinar com os descritores do SAEB de Matemática e utilizar como potencializador de sua aprendizagem.

\section{Fundamentação teórica}

A computação desplugada tem sido recorrente no ensino do pensamento computacional, pois permite que os estudantes sejam estimulados de forma lúdica e divertida, sem a necessidade de artefatos tecnológicos digitais [Lee et al. 2011; 2014]. Para além, Santos et al. [2016] afirma que dessa forma o pensamento computacional aproxima-se de escolas em que os computadores e suas tecnologias não estão disponíveis ou são insuficientes.

Nascimento et al. [2018] indicam como resultados de um mapeamento sistemático sobre o pensamento computacional aliado ao currículo formal, que poucos trabalhos envolvendo a interdisciplinaridade. Segundo os autores, poucas iniciativas apresentam indicadores de como ações como estas podem ser realizadas. O currículo do CIEB, embora seja um grande avanço para a disseminação do pensamento computacional nas escolas, não deve ser compreendido como uma receita pronta. $\mathrm{O}$ documento deve ser compreendido como um instrumento norteador, para que os profissionais da educação percebam como podem integrar e correlacionar as habilidades 
específicas da cultura digital, tecnologias digitais e pensamento computacional com outras habilidades e competências de outras áreas do conhecimento.

Com a ajuda do currículo, espera-se que experiências possam ser realizadas alinhadas às áreas de conhecimentos dos professores ou correlacionadas a outras habilidades da BNCC e de outros sistemas de melhoria da educação básica. Embora a base seja o documento oficial que norteia toda a educação básica, outros instrumentos foram criados, para auxiliar as secretarias educação, escolas, gestores e professores a acompanhar e melhorar seus resultados de aprendizagem dos estudantes.

$\mathrm{Na}$ atual conjuntura, cabe ao Sistema de Avaliação da Educação Básica (SAEB) avaliar o desempenho dos estudante da escola pública brasileira, para fornecer um indicativo sobre a qualidade do ensino ofertado [INEP 2019]. Por meio de provas e questionários, aplicados periodicamente, o SAEB pode contribuir com os gestores estaduais e municipais para que possam avaliar e monitorar a qualidade da educação no país. O sistema utiliza matrizes de referências específicas que aproximam-se das habilidades descritas na base, mas possui algumas especificidades. Essas habilidades são chamadas de descritores. Atualmente, são avaliados estudantes dos $5^{\circ}$ anos e $9^{\circ}$ anos, referente às habilidades relacionadas ao ensino de língua portuguesa e matemática.

\section{Estratégias e ferramentas no ensino de Pensamento Computacional}

Bombasar et al. [2015] revelaram, por meio de uma revisão sistemática de literatura, as ferramentas mais empregadas no ensino do pensamento computacional. Os resultados da revisão indicaram que as ferramentas relacionadas a linguagem de programação visual, como Scratch, são as frequentemente utilizadas. Araújo et al. [2016] executaram um mapeamento sistemático sobre como o pensamento computacional tem sido estimulado e avaliado no Brasil. Os resultados da pesquisa revelaram que programação, testes e códigos são as abordagens e instrumentos mais utilizados no ensino do pensamento computacional e o teste como instrumento de avaliação mais utilizado dentre os artigos analisados. Werlich et al. [2018] indicam que desenvolver o pensamento crítico e a capacidade de resolução de problemas dos estudantes é um problema no processo de ensino e aprendizagem e apontam a técnica de computação desplugada como abordagem a ser empregada para desenvolvimento do pensamento computação. Como resultados, os autores identificaram melhora dos resultados dos estudantes do $2^{\circ}$ anos do ensino fundamental relacionados ao pensamento crítico e criativo quando foram inseridos em atividade coletiva.

\section{Metodologia}

Nesta seção estão descritas as condicionantes e variáveis da pesquisa que culminaram nos resultados do trabalho descrito. Na subseção 4.1, 4.2 e 4.3 é possível identificar o lócus, o público-alvo e a sequência didática criada e utilizada na experiência educativa.

\subsection{Lócus da prática educativa}

A intervenção foi realizada em uma escola pública do município de Tibau do Sul, no estado do Rio Grande do Norte. A escola de educação infantil e anos iniciais atende a aproximadamente 339 estudantes, divididos nos turnos matutino e vespertino. Quanto 
VIII Congresso Brasileiro de Informática na Educação (CBIE 2019)

Anais dos Workshops do VIII Congresso Brasileiro de Informática na Educação (WCBIE 2019)

aos espaços destinados para as práticas educativas formais, consta na escola oito salas de aulas; não formais, há apenas um pátio. Em relação a infraestrutura tecnológica, a instituição possui um notebook e um projetor que são utilizados por todos os professores, coordenadores e gestores da escola.

Esta realidade de escassez tecnológica foi levada em conta para permitir pensar em uma proposta coerente com o contexto local e tecnologicamente possível de ser replicada pelos professores da escola.

\subsection{Sujeitos envolvidos}

A pesquisa foi realizada junto a uma turma do $5^{\circ}$ ano do turno vespertino, composta por 20 alunos de idades entre 10 e 14 anos. Segundo os dados oficiais do boletim de desempenho da escola de 2015, os alunos estão inseridos em um contexto socioeconômico médio baixo, conforme a nota técnica de indicador de nível socioeconômico (INSE) do Instituto Nacional de Estudos e Pesquisas Educacionais (INEP) [INEP 2015].

O nível socioeconômico dos estudantes foi relevante na pesquisa para desenvolvimento da proposta pedagógica, pois a partir da realidade social foi possível identificar que recursos e elementos poderiam ser incluídos na sequência didática. Caso os estudantes tivessem acesso à celulares, esse tipo de dispositivo poderia ser inserido individual ou coletivamente na proposta educativa à utilização de jogos digitais.

\subsection{Sequência didática utilizada na experiência educativa}

Para estimular o pensamento computacional alinhado aos descritores do SAEB foi utilizado uma sequência didática subdividida em duas etapas, em dois dias de aula. A primeira etapa teve como objetivo apresentar e estimular o pensamento computacional em suas quatro dimensões. Na etapa seguinte, a sequência didática pautou-se em trabalhar o pensamento computacional relacionando-o a cinco descritores da avaliação do SAEB.

Os descritores selecionados são:

- D23 - Resolver problema utilizando a escrita decimal de cédulas e moedas do sistema monetário brasileiro;

- D27 - Ler informações e dados apresentados em tabelas;

- D11 - Resolver problema envolvendo o cálculo do perímetro de figuras planas, desenhadas em malhas quadriculadas;

- D10 - Num problema, estabelecer trocas entre cédulas e moedas do sistema monetário brasileiro em função de seus valores;

- D1 - Identificar a localização e movimentação de objetos em mapas, croquis e outras representações gráficas.

A seleção desses descritores deu-se em razão das necessidades formativas dos estudantes. Conforme o boletim de desempenho da escola de 2015, apenas 17,57\%, $12,65 \%, 2,13 \%$ e $2,13 \%$ dos estudantes obtiveram, respectivamente, índices de proficiência em conhecimentos relacionados aos descritores D1, D11, D10 e D27. 
VIII Congresso Brasileiro de Informática na Educação (CBIE 2019)

Anais dos Workshops do VIII Congresso Brasileiro de Informática na Educação (WCBIE 2019)

A primeira etapa foi organizada com atividades de computação desplugada, abordando o pensamento computacional em suas dimensões: decomposição, abstração, reconhecimento de padrões e algoritmo. Inicialmente, foi feito uma conversa com a turma tomando como base as seguintes perguntas: vocês sabem e gostam de jogar? Já se imaginaram criando seus próprios jogos? A partir de então, foi introduzido algumas atividades que abordavam sobre os princípios de execução e comandos de jogo, reconhecimento de padrões com figuras de formas geométricas e em formato de frutas, e simulação e hipóteses de comandos com fins de descobrir novas maneiras de executar o jogo.

As atividades utilizadas na prática educativa tiveram como objetivo aproximar os estudantes de conceitos específicos do pensamento computacional e apresentá-los a computação desplugada em formato de atividade gamificada (ver Figura 1).
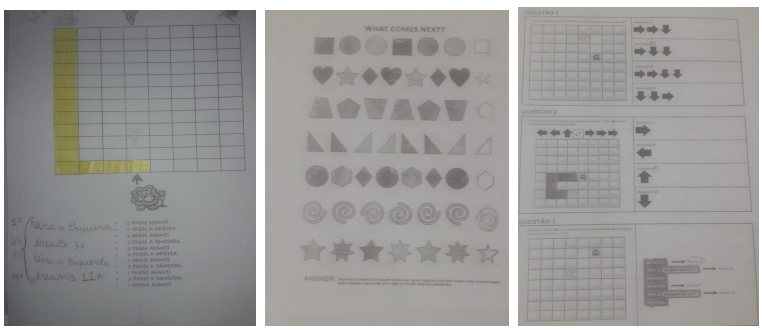

Figura 1. Atividades em folha de decomposição, algoritmo e reconhecimento de padrões

No segundo momento da aula, foi realizado uma avaliação utilizando o aplicativo plickers [2018] (ver Figura 2), elaborado previamente com cinco questões semelhantes a sequência de atividades anteriormente desenvolvidas com a turma. Inicialmente, foi necessário explicar para os estudantes como funcionava o QR Code. $\mathrm{O}$ objetivo da explicação foi orientar as crianças para que não se atrapalhassem na hora de responder às questões.

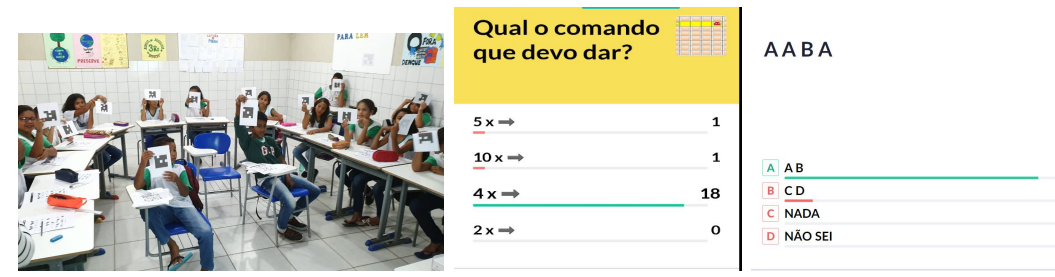

Figura 2. Avaliação da aprendizagem utilizando o plickers

Após as atividades desplugadas, o site hora do código foi explorado com os estudantes por meio do computador e do projetor da escola. A turma foi dividida em dois grupos e os estudantes foram desafiados a desenvolver soluções para as situações apresentadas. Assim, encerrou-se a primeira etapa da proposta educativa.

A etapa seguinte da sequência didática consistiu-se na aplicação de um jogo desplugado com vistas a incentivar o pensamento computacional alinhado aos descritores. Para essa aula, foi organizado previamente o jogo caça pensamento computacional $^{\text {. }}$.

\footnotetext{
${ }^{1}$ Jogo Caça pensamento computacional:
} 
VIII Congresso Brasileiro de Informática na Educação (CBIE 2019)

Anais dos Workshops do VIII Congresso Brasileiro de Informática na Educação (WCBIE 2019)

O jogo caça pensamento computacional teve como princípio a utilização de malha quadriculada (tabuleiro) desenhada com fita adesiva gomada no chão da escola (ver Figura 3). O tabuleiro foi desenhado com dimensões de A a J e de -5 a 5 . Os alunos se dispuseram a ajudar na construção do tabuleiro. Para os alunos, era o primeiro contato que estavam tendo como "programadores" e mostraram-se disponíveis para colocar a "mão na massa", auxiliando os professores nas situações rotineiras de ensino e aprendizagem.

O incentivo à participação dos estudantes na construção do tabuleiro na sala foi importante para que eles fossem envolvidos na organização e compreendessem as regras do jogo. Os professores envolvidos, comunicaram aos estudantes a importância que não havia nada "fechado", que poderiam ser ousados e criar, recriar, fazer e desfazer.

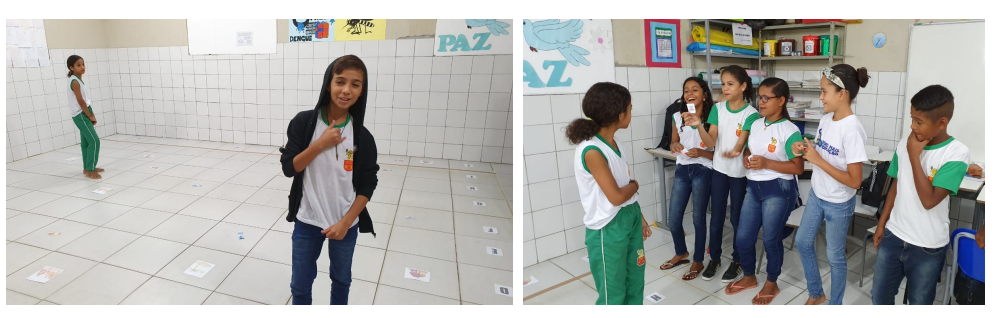

Figura 3. Aplicação do jogo caça pensamento computacional

No link a seguir é possível acessar um documento que descreve o jogo e os resultados esperados em cada etapa:https://drive.google.com/open?id=1bkkPrso_oisgt5vwwV_huz0Yk4_hqc15AiEzq JSMTnE. Os descritores foram inseridos nas cartas-desafios entregues aos grupos, as respostas poderiam ser encontradas utilizando a malha quadriculada. As cartas estavam dispostas em algumas células do tabuleiro, juntamente com alguns obstáculos e as cédulas que os estudantes deveriam coletar para depositar no banco.

\section{Resultados e discussões}

No contexto da aplicação, a sequência didática mostrou-se válida e coerente com a realidade da turma que participou da intervenção. A organização da proposta permitiu que os estudantes vivenciassem e compreendessem os conceitos de programação, reconhecimento de padrões e resolução de problemas de forma teórica e prática.

A sequência, subdividida em duas etapas, garantiu que os estudantes fossem estimulados previamente sobre o pensamento computacional relacionado com conceitos de matemática e, depois, aplicando esse novo conhecimento de forma prática e imersivo. A proposta do primeiro dia em que os estudantes foram estimulados sobre as dimensões do pensamento computacional com atividades gamificada em folha, foi fundamental para que os estudantes compreendessem do objetivo da proposta. $\mathrm{Na}$ ocasião, os estudantes também perceberam como funcionava as operações e os comandos a serem utilizados, posteriormente, no jogo.

Os estudantes compreenderam a proposta e não tiveram dificuldades em relacionar os conceitos de pensamento computacional com a prática. A utilização das

<https://drive.google.com/open?id=10i3mScCNgznhkL1ST87aCx3SGiLwn5COPBTKIbhOsjQ> 
atividades desplugadas para ensinar os conceitos de pensamento computacional foram determinantes, pois ao escreverem os passos a serem utilizados para solucionar um determinado problema, os estudantes conseguiram aplicar os conceitos de abstração, decomposição e algoritmo. Nesta etapa da prática educativa, foi observado que os alunos tiveram dificuldades iniciais em compreender os conceitos de direita e esquerda, relacionados a lateralidade. Dessa forma, as atividades auxiliaram na construção de esquemas mentais dos estudantes a respeito dessas definições tão importantes para o desempenho de atividades rotineiras envolvendo localização e noções espaciais.

Como avaliação da internalização aprendizagens estimuladas, foi aplicado o plickers. A avaliação ratificou o que foi observado pelos aplicadores da experiência. Pois que, dos 20 alunos presentes e participantes da ação, apenas 2 não responderam corretamente todas as questões. As questões foram criadas baseadas nas atividades desenvolvidas no início da primeira etapa. Alguns pontos singulares observados pelos pesquisadores diz respeito ao quanto os alunos estão abertos a aprenderem novos conhecimentos. Bastava uma explicação para conseguirem fazer as demais etapas sozinhos. Em todos os momentos os alunos se sentiam motivados em realizar as atividades, favorecendo a reflexão e a compreensão dos objetivos propostos. Não foi identificado nos estudantes a presença de desinteresse ou desconforto com as atividades.

Com relação a aplicação da segunda etapa da sequência didática, os alunos demonstraram interesse em participar de todas as etapas de organização da montagem do jogo. A partir disso reconhece-se o quanto é importante estimular esse interesse por parte dos alunos na construção das atividades em que possam contribuir desde a sua criação. Na condução da vivência do jogo os alunos rapidamente entenderam a proposta e as regras, mas foram descartadas as cartas-perguntas, pois que os alunos não compreendiam. Diante disso, constata-se que há uma dificuldade por parte da turma em resolver situações-problemas com malha quadriculada, que lêem, mas não compreendem o problema. Por outro lado, a análise preliminar mostra que os alunos parecem demonstrar facilidade em identificar padrões de problemas. No jogo aplicado, verificou-se uma significativa melhora na sequência de programação, que ocasionou em uma disputa mais acirrada para a coleta de mais cédulas, permitindo que os estudante pensassem rapidamente em uma programação de modo a chegar nas casas onde tinha cédulas.

Quanto às concepções dos alunos sobre a proposta, foi observado que os aspectos mais relevantes para os alunos são incorporados nas atividades "novas", na disputa e no que eles constroem. Demonstraram que compreendem regras e conseguem resolver problemas simples com o sistema monetário. Na programação são criativos e estrategistas e a faz com ajuda da reflexão sobre cada comando. O professor da turma quanto observador das sequências aplicada pelos pesquisadores pôde contribuir no decorrer das atividades respondendo a perguntas sobre a proposta realizada em sua turma. E, quando questionado sobre a importância da vivência de computação desplugada para atingir os objetivos da SAEB, o professor acredita que havendo mais atividades como esta, os alunos podem desenvolver melhor o raciocínio lógico e, consequentemente, fazer uma boa prova.

Os resultados da aplicação da proposta pedagógica indicam que os estudantes envolvidos na experiência conseguiram avançar nos seguintes pontos: compreensão 
sobre o que é o pensamento computacional e suas dimensões; exercício de pensar sobre seu próprio pensamento; e expressar de forma lógica a construção de passos para solucionar os problemas propostos pelo mediador. Quanto às habilidades relacionadas a avaliação do SAEB, a experiência foi significativa para o professor e para os estudantes, pois ambos conseguiram perceber a utilização das habilidades avaliadas de outras maneiras. Em relação às contribuições da experiência para os estudantes, a intervenção provocou-lhes a utilização de habilidades e competências alinhadas ao pensamento computacional que apenas havia sido visto de forma teórica e tradicional.

\section{Considerações finais}

Para muitas escolas, professores e alunos, o Pensamento Computacional ainda é algo novo. É um tema que desperta a curiosidade e o interesse dos estudantes e a curiosidade dos professores. Ainda que se reconheça que há muito ainda a ser avançado nesse sentido, a experiência realizada, mediante intervenção em sala de aula, conseguiu atingir seus os objetivos. Ao estimular uma prática diversificada, coerente com as condições da escola, de forma interdisciplinar, utilizando pensamento computacional, a intervenção apresentou aos professores da escola como poderiam integrar os recursos, os conhecimentos específicos e o pensamento computacional em suas aulas.

A proposta do jogo desplugado envolvendo os descritores do SAEB foi importante para que o professor da turma pudesse refletir sobre sua prática e diversificar as metodologias para ensinar de forma a proporcionar ao aluno um aprofundamento no conteúdo de forma imersiva e lúdica.

Uma das dificuldades encontradas na aplicação da proposta (atividades desplugadas e jogo) foi o conhecimento dos alunos sobre os conteúdos relacionados aos descritores a serem trabalhados utilizando pensamento computacional. Os estudantes expressaram dificuldades em abstrair e identificar na malha quadriculada às figuras planas, assim como conceitos de lateralidade (direita, esquerda). Essas dificuldades também representam a validade de toda a proposta, pois as atividades desplugadas em folha e o jogo estimularam os estudantes a perceberem que precisavam avançar, sendo, portanto, um recurso de avaliação autoregulada. Outro desafio diz respeito à continuidade dessas práticas na turma do professor em razão de formação para a utilização e criação de sequência didática interdisciplinar utilizando pensamento computação em suas diversas abordagens. Em resumo, com a experiência, foi possível ratificar que o pensamento computacional pode ser utilizado de forma desplugada, contribuindo assim, de forma positiva, na aquisição de conhecimentos acerca de resolução de problemas e reconhecimentos de padrões, bem como desenvolvimento do senso crítico para os conteúdos ministrados em sala de aula de forma a atingir os descritores da avaliação SAEB. Como trabalhos futuros pretende-se utilizar essa experiência como referencial teórico e prático para o desenvolvimento de um estudo sobre a formação de professores com foco no pensamento computacional, em nível de pós-graduação (mestrado profissional).

\section{Referências}


VIII Congresso Brasileiro de Informática na Educação (CBIE 2019)

Anais dos Workshops do VIII Congresso Brasileiro de Informática na Educação (WCBIE 2019)

Araujo, A. L., Andrade W. and Guerrero D. (2016). Um Mapeamento Sistemático sobre a Avaliação do Pensamento Computacional no Brasil. Anais dos Workshops do Congresso Brasileiro de Informática na Educação. Vol. 5. No. 1.

Blikstein, P. (2008). "O Pensamento Computacional e a Reinvenção do Computador na Educação". Disponível em: < http://bit.ly/1lXlbNn>. Acesso em: 27/10/2019.

Bombasar, J.; Raabe, A.; Miranda, E. M. e Santiago, R. (2015). Ferramentas para o ensino-aprendizagem do pensamento computacional: onde está Alan Turing? In: Anais do XXVI Simpósio Brasileiro de Informática na Escola. p. 81.

Brasil. Base Nacional Comum Curricular (BNCC). (2018). Educação infantil e Ensino fundamental. Brasília: MEC. Disponível em: http://basenacionalcomum.mec.gov.br/images/BNCC_EI_EF_110518_versaofinal_si te.pdf Acesso em: 28/09/2019.

INEP, Índice de Desenvolvimento da Educação Básica (Desempenho da escola), 2015. Disponivel em: <http://sistemasprovabrasil.inep.gov.br/provaBrasilResultados/> Acesso em: 27/09/2019.

INEP, Índice de Desenvolvimento da Educação Básica (Indicador de Nível Socioeconômico das Escolas de Educação Básica (Inse)), (2015). Disponivel em: <http://portal.inep.gov.br/indicadores-educacionais> Acesso em: 28/09/2019.

Lee, I., Martin, F., \& Apone, K. (2014). Integration of computational thinking in curriculum K - 8. Acm Inroads , 5 (4), 64-71.

Lee, I.; Martin, F.; Denner, J. et al. Computational thinking for youth in practice. ACM Inroads, v. 2, n. 1, p. 32-37, fev 2011.

Nascimento, C., Santos, D. A., \& Tanzi, A. (2018). Pensamento Computacional e Interdisciplinaridade na Educação Básica: um Mapeamento Sistemático. In Anais dos Workshops do Congresso Brasileiro de Informática na Educação (Vol. 7, No. 1, p. 709).

Papert, S. (1994). A máquina das crianças. Porto Alegre: Artmed.

Santos, E. R. et al. (2016) Estímulo ao Pensamento Computacional a partir da Computação Desplugada: uma proposta para Educação Infantil. Revista Latinoamericana de Tecnología Educativa, Porto Alegre, v. 15, p.99-112, Semestral. Disponível em: < https://bit.ly/2pkOFh7>. Acesso em: 28/09/2019.

Valente, J. A. (2016). Integração do pensamento computacional no currículo da educação básica: diferentes estratégias usadas e questões de formação de professores e avaliação do aluno. Revista e-Curriculum, 14(3), 864-897.

WEF. The Future of Jobs Report 2018, World Economic Forum, Geneve.

Werlich, C., Crema, C., Kemczinski, A., \& Gasparini, I. (2018). Pensamento Computacional no Ensino Fundamental I: um estudo de caso utilizando Computação Desplugada. In Anais dos Workshops do Congresso Brasileiro de Informática na Educação (Vol. 7, No. 1, p. 719). 
VIII Congresso Brasileiro de Informática na Educação (CBIE 2019)

Anais dos Workshops do VIII Congresso Brasileiro de Informática na Educação (WCBIE 2019)

Wing, J. M. (2006). "Computational Thinking”. Communications of the ACM. March, Vol. 49, No. 13 